\title{
OPEN $\mathrm{AlO}_{6}$ clusters' electric storage effect in amorphous alumina supercapacitors
}

\author{
Mikio Fukuhara ${ }^{1 凶}$, Tomoyuki Kuroda ${ }^{1}$, Fumihiko Hasegawa ${ }^{1}$, Toshiyuki Hashida ${ }^{2}$, \\ Mitsuhiro Takeda ${ }^{3}$, Kazuya Konno ${ }^{3}$ \& Nobuhisa Fujima ${ }^{4}$
}

In this study, the electric storage effect of $\mathrm{AlO}_{6}$ clusters in amorphous alumina (AAO) supercapacitors was investigated in terms of cluster morphologies under electron-beam irradiation. Based on firstprinciples density functional calculation, the optimised structure of $\mathrm{AlO}_{6}$ clusters around an $\mathrm{O}$-vacancy is characterised by a large vacant space created by the absence of an $\mathrm{O}$ atom and its neighbouring $\mathrm{Al}$ atom. The localised electrons present near the two-atomic vacancies induce positive charges on the inside of the insulating oxide surface, ensuring the adsorption of many electrons on the surface. Electron-beam irradiation (adsorption) from 100 to $180 \mathrm{keV}$ causes the lengths of the Al-O bonds of the cluster to shrink, but then return to the original length with decreasing voltage energy, indicating a rocking-chair-type charge-breathing effect accompanied by a volume expansion of approximately $4 \%$. The $I-V$ and $I-R$ characteristics depicted Coulomb blockade for the switching effect of both the negative and positive potentials. The Ragone plot of the AAO supercapacitor is located at capability area of the second cell.

The most popular electrochemical capacitor is an electric double-layer supercapacitor (SC) where the interfaces of high specific-area materials such as porous carbon materials or porous metal oxides of some metals are charged and discharged by ion or radical diffusion ${ }^{1-3}$. In sharp contrast to the conventional SC, we developed physical dry ones based on both the quantum-size effect and the offset effect of the positive charges on uneven insulating material surfaces. An amorphous aluminium-oxide (AAO) device can store a large amount of electric charge as a supercapacitor with various electrical applications. The storage potential of AAO is given by the presence of $\mathrm{AlO}_{6}$ clusters with $\mathrm{O}$-vacancy sites on its blackish, nanometre-sized, uneven $\mathrm{Al}_{2} \mathrm{O}_{3-\mathrm{x}}$ surface ${ }^{4,5}$. Although the six-coordinated $\mathrm{AlO}_{6}$ species are minor components, we could fabricate the AAO film of an $\mathrm{AlO}_{6}$ octahedron on the aluminium surface through the anodic polarisation process with nanometre-sized bubbles of carbon oxide $^{6}$, using $\mathrm{AlY}_{10}$ amorphous alloy ribbons ${ }^{7}$. The film indicated a switching effect for both positive and negative potentials in air, demonstrating the potential of using rechargeable dry solid supercapacitors instead of practical Li ions. To explain why the supercapacitor featured superior electric storage, we first demonstrated the extremely enhanced electron trapping due to both the quantum-size effect and the offset effect caused by positive charges at the oxygen-vacancy sites.

Our current interest lies in studying the electrostatic role of induced electrons in the structural morphology of $\mathrm{AlO}_{6}$ clusters for superior electric storage. In this study, we first analyse cluster morphology as a function of applied electron-beam irradiation with the help of the first-principles simulation (molecular dynamics calculation) method. We assume that the cluster morphology with atomic vacancies under electron-beam radiation (adsorption) provides useful information for the interpretation of the electron charging mechanism of $\mathrm{AlO}_{6}$ clusters. Nakamura et al. ${ }^{8}$ reported that the crystallisation of AAO can be attributed to electron-beam irradiation. However, to the best of our knowledge, no prior research has been conducted on the electron-induced structural morphology of $\mathrm{AlO}_{6}$ clusters in the context of supercapacitors. Cluster morphology, with atomic vacancies, provides new insights into the electronics of nanometre-sized clusters.

\footnotetext{
${ }^{1} \mathrm{New}$ Industry Creation Hatchery Center, Tohoku University, Sendai 980-8579, Japan. ${ }^{2}$ Fracture and Reliability Research Institute, Graduate School of Engineering, Tohoku University, Sendai 980-8579, Japan. ${ }^{3}$ National Institute of Technology, Sendai College, Natori 981-1239, Japan. ${ }^{4}$ Faculty of Engineering, Shizuoka University, Hamamatsu 432-8561, Japan. ${ }^{\boxplus e m a i l: ~ m i k i o . f u k u h a r a . b 2 @ t o h o k u . a c . j p ~}$
} 

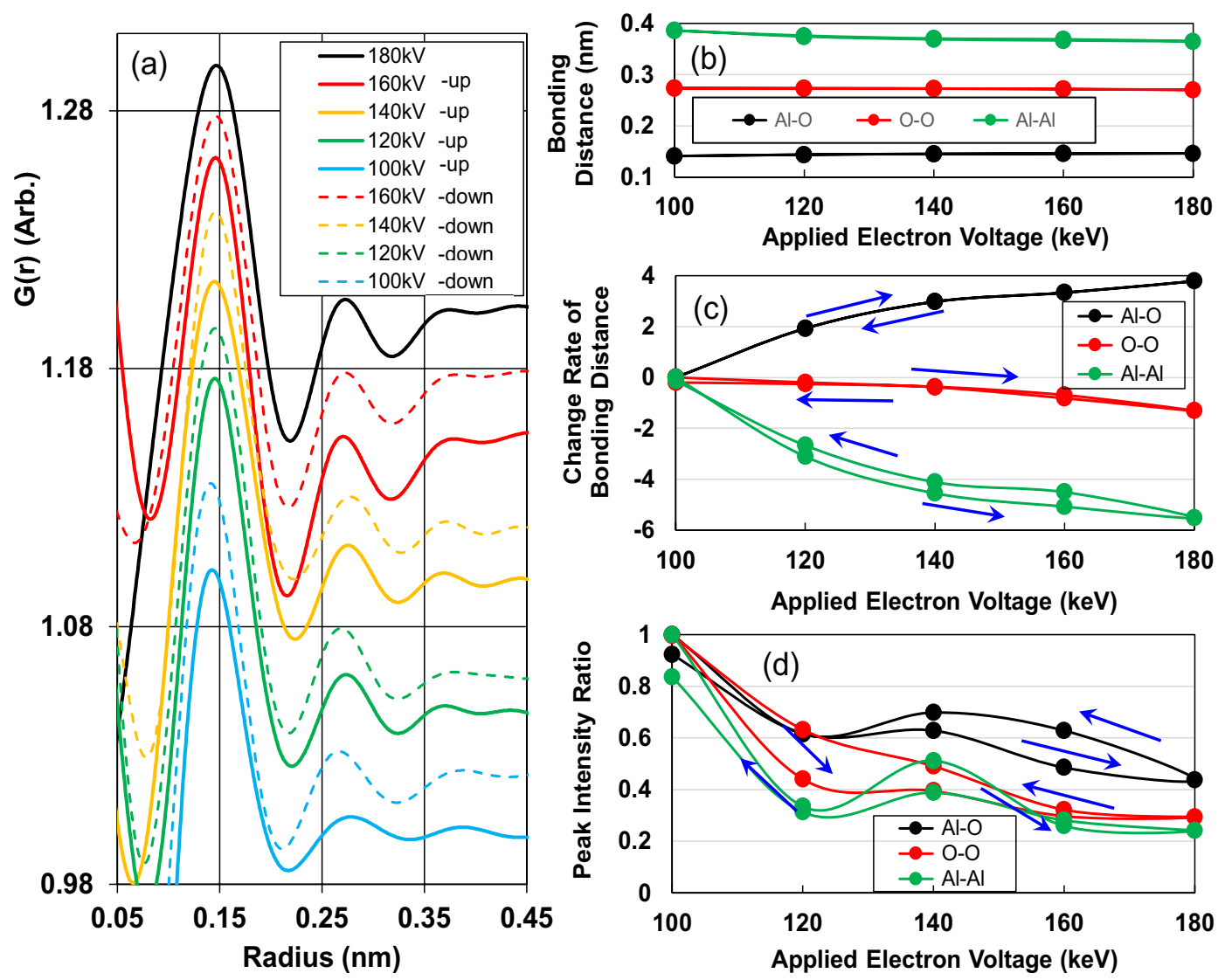

Figure 1. (a) Changes in atomic pair distribution functions (PDFs) under irradiation at 100, 120, 140, 160, and $180 \mathrm{keV}$ with the dose rate of $6 \mathrm{nA} / \mathrm{m}^{2}$ with increasing and decreasing voltage energy runs. (b) Bonding distances, (c) change rates of distance, and (d) intensity ratios for peaks of $\mathrm{Al}-\mathrm{O}, \mathrm{O}-\mathrm{O}$, and $\mathrm{Al}-\mathrm{Al}$ bonds as functions of applied voltage.

\section{Results and discussion}

Structure change of $\mathrm{AlO}_{6}$ clusters under electron-beam irradiation. Because electron radiation at high dose rates of $10^{17} \mathrm{e} / \mathrm{m}^{2}$ s crystallises $\mathrm{AlO}_{6}$ clusters (see Supplementary Information S2), we investigated the cluster morphology of $\mathrm{AlO}_{6}$ clusters at $100-180 \mathrm{keV}$, with a dose rate of $10^{9} \mathrm{e} / \mathrm{m}^{2} \mathrm{~s}$, in terms of the electroncharging mechanism. Figure la shows the changes in atomic pair distribution functions (PDFs) under irradiation at $100-180 \mathrm{keV}$ in increasing and decreasing voltage energy runs. The intensity-peaks of the Al-O, O-O, and $\mathrm{Al}-\mathrm{Al}$ bonds can be observed at approximately $0.15,0.27$, and $0.38 \mathrm{~nm}$, respectively. The lengths of the $\mathrm{Al}-\mathrm{O}$ and $\mathrm{O}-\mathrm{O}$ bonds are smaller, and those of the $\mathrm{Al}-\mathrm{Al}$ bonds are larger than the lengths obtained experimentally or through simulated PDFs of amorphous alumina composed of $\mathrm{AlO}_{4}$ or $\mathrm{AlO}_{5}$ clusters $^{9-12}$. The bonding distances and change rates of distance for the $\mathrm{Al}-\mathrm{O}, \mathrm{O}-\mathrm{O}$ and $\mathrm{Al}-\mathrm{Al}$ bonds as functions of applied voltage energy are presented in Fig. $1 \mathrm{~b}$ and c, respectively. Compared with the shrinkage of the $\mathrm{O}-\mathrm{O}$ and $\mathrm{Al}-\mathrm{Al}$ bonds, the length of the $\mathrm{Al}-\mathrm{O}$ bond increases by as much as $4 \%$ and then returns to zero as the applied voltage energy increases from 100 to $180 \mathrm{keV}$ and decreases to $100 \mathrm{keV}$. Because the first peak of $\mathrm{Al}-\mathrm{O}$ is affected by insufficient electron intensity, we considered only the $\mathrm{O}-\mathrm{O}$ and $\mathrm{Al}-\mathrm{Al}$ peaks in this study. The peak intensity ratios of $120,140,160$, and $180 \mathrm{keV}$ to peak intensity of $100 \mathrm{keV}$ (Fig. 1d) approximately decrease with increasing applied voltage energy up to $180 \mathrm{keV}$ and then increase when the applied voltage energy is decreased to $100 \mathrm{keV}$. However, none of the peaks overcome the peak intensity at $100 \mathrm{keV}$. Because crystallisation of $\gamma-\mathrm{Al}_{2} \mathrm{O}_{3}$ with a long-period structure is accompanied by an increase in the peak intensity of the $\mathrm{O}-\mathrm{O}$ and $\mathrm{Al}-\mathrm{Al}$ bonds ${ }^{9}$, the structural morphology of the $\mathrm{AlO}_{6}$ cluster is stable against electronic excitation up to $180 \mathrm{keV}$. Yong et al. ${ }^{13}$ also reported that amorphous alumina separated $\mathrm{O}^{2-}$ gas bubbles when it was irradiated at an energy of $200 \mathrm{keV}$ and a beam current of $5.4 \times 10^{-10} \mathrm{~A}$. Thus, the critical voltage energy of $180 \mathrm{keV}$ is higher than those of 100 and $150 \mathrm{keV}$ for metal ( Na, $\mathrm{Li}, \mathrm{K}, \mathrm{Pb}$, and $\mathrm{Ag}$ ) $\beta$-alumina ${ }^{14}$ and silicon nitride ${ }^{15}$, respectively.

Optimised structure of $\mathrm{AlO}_{6}$ clusters and its electronic role. Next, we simulated the optimised structure around the $\mathrm{AlO}_{6}$ clusters. We derived the relationship between energy and average atomic distance between the $\mathrm{O}$ vacancy and the vacancies in the neighbouring $\mathrm{Al}$ atoms using the molecular dynamic method. The calculated results are presented in Fig. 2a. The larger the average distance, the higher the energy required for stability, thereby bringing the neighbouring $\mathrm{O}$ atoms closer. Thus, we can optimise the local structure of the $\mathrm{AlO}_{6}$ 

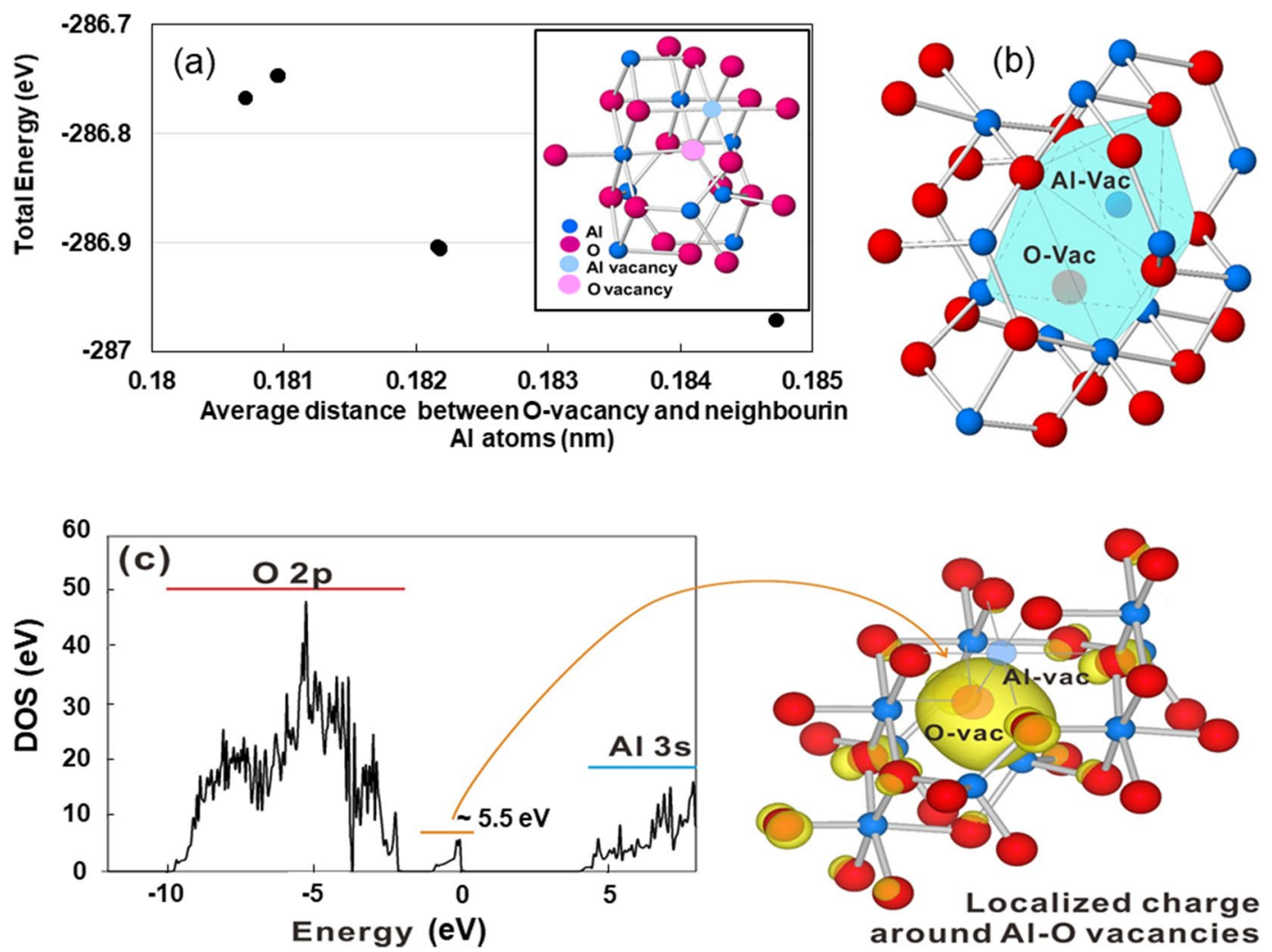

Figure 2. (a) Relation between energy and atomic distance between $\mathrm{O}$ vacancy and its neighbouring $\mathrm{Al}$ vacancies. Inset in (a): Optimised structure of $\mathrm{AlO}_{6}$ cluster with oxygen and aluminium vacancies. (b) Vacant cage produced by deficit of an $\mathrm{O}$ atom and its neighbouring $\mathrm{Al}$ atom in $\mathrm{AlO}_{6}$ cluster. (c) Density of state for $\mathrm{O} 2 p$ and $\mathrm{Al} 3 s$ in $\mathrm{AlO}_{6}$ cluster. Isolated electronic state locally occurs in vicinity of two-atom vacancies.

cluster unit $\left(\mathrm{Al}_{2} \mathrm{O}_{2.875}\right.$ with a density of 2.79), which has a shortage of neighbouring $\mathrm{O}$ and $\mathrm{Al}$ atoms, as depicted in the inset in Fig. 2a. We then simulated the density of states (DOS) for the $\mathrm{O} 2 p$ and $\mathrm{Al} 3 s$ electrons of the $\mathrm{AlO}_{6}$ cluster. Figure $2 c$ depicts an isolated electronic state in the band gap, which locally occurs in the vicinity of the $\mathrm{O}$ vacancy and its neighbouring $\mathrm{Al}$ vacancies. The existence of an electronic state in insulating oxide clusters provides new insights into the electronics of amorphous oxides with nanometre-sized clusters. Indeed, amorphous titanium-oxide (ATO) supercapacitors are characterised by electrostatic induction of a large positive charge on the uneven oxide surface based on the electronic conduction state derived from $\mathrm{TiO}_{2} / \mathrm{VO}_{2}$ nanostructural interfaces in the oxide ${ }^{16}$. The cage structure consists of a vacant space of $0.0214 \mathrm{~nm}^{3}$, as represented in Fig. $2 \mathrm{~b}$.

An electric storage system of $\mathrm{AlO}_{6}$ clusters. From the shrinkage of the $\mathrm{Al}-\mathrm{Al}$ bond length under irradiation energies of 100-180 keV, as depicted in Fig. 1c, we calculated the electrostatic potential and electron pressure of $\mathrm{Al}$ and the electrostatic compressive pressure induced by electron adsorption as a function of applied irradiation energy (see Supplementary Information S6). The results are presented in Fig. 3a. The electron pressure of the $\mathrm{Al}$ atom gradually increases and decreases as the applied electron energy increases up to $180 \mathrm{keV}$ and returns to $100 \mathrm{keV}$, respectively, while the electrostatic potential decreases to $-22 \mathrm{eV}$ at $180 \mathrm{keV}$ and returns to - $19.7 \mathrm{eV}$ at $100 \mathrm{keV}$. Here, we considered the Maxwell stress (electric field stress), which performs mechanical work in contracting the thickness of the vacancy cages (Fig. 2b) enclosing the two atomic vacancies in the $\mathrm{AlO}_{6}$ cluster. Maxwell compression increases from 1.3 to $4.1 \mathrm{GPa}$, accompanied by a volume shrinkage of nearly $4 \%$ (Fig. 3b), according to applied electron voltage energies (see Supplementary Information S4), and returns to 1.3 $\mathrm{GPa}$ at $100 \mathrm{keV}$. From the measurement of bulk modulus for the $\mathrm{AlO}_{6}$ cluster, we indeed obtained $4.1 \mathrm{GPa}$ using $\Delta \mathrm{V} / \mathrm{V}$ at $180 \mathrm{keV}$, where $\Delta \mathrm{V}$ is the change in volume V (see Supplementary Information S5). Here, it should be noted that lattice contractions have been observed for fine metallic particles such as silver ${ }^{17}$, copper, platinum ${ }^{18}$, and gold ${ }^{19}$. This is indicated by the increase in electrostatic force induced by electron screening ${ }^{20}$. Hence, we infer by analogy that electron-beam irradiation (adsorption of electrons) causes the $\mathrm{AlO}_{6}$ cluster to shrink owing to the electrostatic attraction force induced by the screened-electrons among the $\mathrm{Al}$ atoms (lower inset in Fig. 3b). The schematic for electro adsorption induced by electron-beam irradiation is presented in the upper inset of Fig. 3b. The localised electrons present near the two-atomic vacancies in the $\mathrm{AlO}_{6}$ cluster induce positive charges on the inside of the insulating oxide surface, resulting in the adsorption of many electrons under electron-beam irradiation. However, when the value of the applied irradiation energy returned to $100 \mathrm{keV}$, we obtained the same PDF as that observed at the starting voltage of $100 \mathrm{keV}$. This indicates the desorption of electrons due to the volume recovery of the vacancy cage. The $\mathrm{AlO}_{6}$ cluster seems to have a 'rocking -chair-type' electric storage 

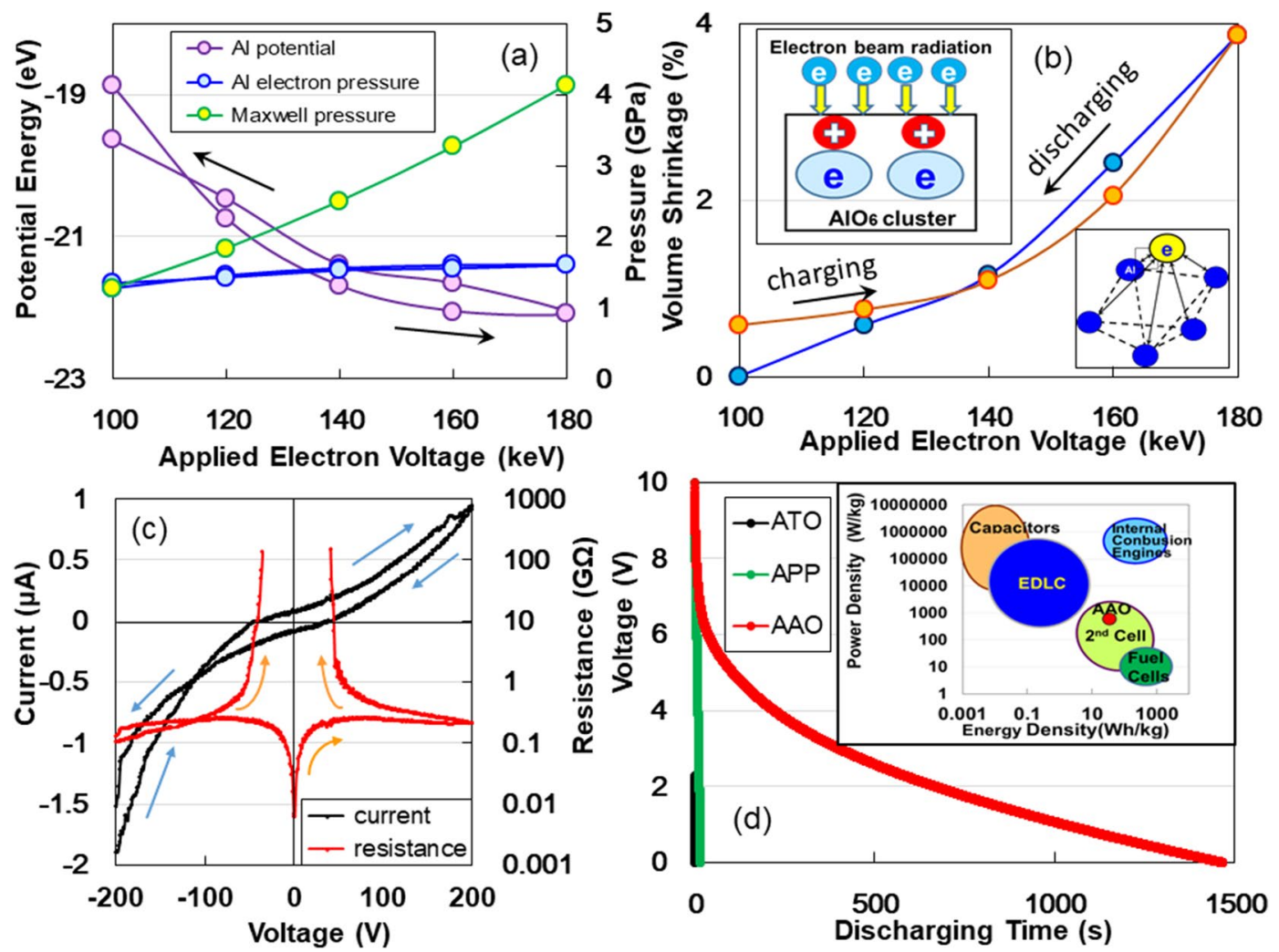

Figure 3. (a) Al potential, $\mathrm{Al}$ electron pressure and Maxwell stress, and (b) volume shrinkage as a function of applied electron voltage energy. Upper inset in (b): Schematic shrinkage model explaining huge electric storage for $\mathrm{AlO}_{6}$ cluster with two atom vacancies. Lower inset of (b): Shrinking model of $\mathrm{AlO}_{6}$ cluster by electrostatic attraction force among $\mathrm{Al}$ atoms induced by screened electrons. (c) $I-V$ and $R-V$ characteristics from -200 to $+200 \mathrm{~V}$. (d) Charging/discharging behaviours for ATO, APP, and AAO. Inset in (d): Comparison of power density and energy density for AAO (this study), APP, EDLC, batteries, fuel cells, and internal combustion energies (based on Whittingham's study ${ }^{22}$ ).

system similar to a breathing lung. The amorphous materials of interest can be distinguish between 'dry' body and 'wet' cells such as electric double-layer capacitors (EDLCs) and secondary cells, which are controlled by ion diffusivity.

Electricity switching effect of rechargeable dry solid supercapacitors. Our study presents further evidence of large electron storage values for rechargeable dry solid supercapacitors using the AAO device. Figure $3 \mathrm{c}$ represents the double $I-V$ and $R-V$ characteristics obtained by DC current method between -200 and $+200 \mathrm{~V}$ in air at $293 \mathrm{~K}$. The $I-V$ curves indicate nonlinear electronic transport behaviour, which is similar to the Coulomb blockade behaviour observed in a metal-semiconductor junction which is characterized by a Schottky junction ${ }^{21}$. We can see the 'Coulomb gap' depicted by the hyperbolic curves in the $R-V$ characteristics. The $I-V$ curves are asymmetric with respect to zero bias. Although the asymmetry could be generally attributed to the specimen size ${ }^{22}$, the current $I$ reached zero at -35.6 and $+35.6 \mathrm{~V}$ upon increasing and decreasing the applied voltage $V$, respectively. Zero current at $-35.6 \mathrm{~V}$ corresponds to the emission of electrons from the negative electrode to the convex portions, whereas zero current at $+35.6 \mathrm{~V}$ indicates the emission of electrons from the concave portions to the positive electrode, as described in our previous paper ${ }^{5}$. This is further evidence of the electricity switching effect of rechargeable dry solid supercapacitors.

Figure $3 \mathrm{~d}$ depicts the discharging behaviour of AAO, ATO, and amorphous perfluorinated polymer (APP) under a constant current of $1 \mathrm{nA}$ after charging by DC currents of $1 \mathrm{~mA}$ for $240 \mathrm{~s}$. The discharging curves do not match the standard trace, which is typical for conventional supercapacitors. This can be explained by electroadsorption ${ }^{23}$ occurring on nanometre-sized capacitors. The discharging time of AAO is approximately 3000 and 100 times longer than those of $\mathrm{ATO}^{7}$ and $\mathrm{APP}^{24}$, respectively.

Since the discharging curve for AAO in Fig. 3d indicates an electric power of $2.43 \times 10^{-9} \mathrm{~W}$ and electric energy of $9.90 \times 10^{-10} \mathrm{Wh}$, we obtained a power density of $115.4 \mathrm{~W} / \mathrm{kg}$ and an energy density of $47.0 \mathrm{Wh} / \mathrm{kg}$ (see Supplementary Information S7). The Ragone plot, the relation between energy density and power density, for the AAO supercapacitor is presented in the inset of Fig. 3d, along with conventional capacitors, EDLC, and the second fuel cells ${ }^{25}$. The plot of the AAO supercapacitor is located at capability area of the second cell. Thus, we can apply rechargeable dry supercapacitors instead of practical Li ions in a liquid solvent. The quick, powerful, 

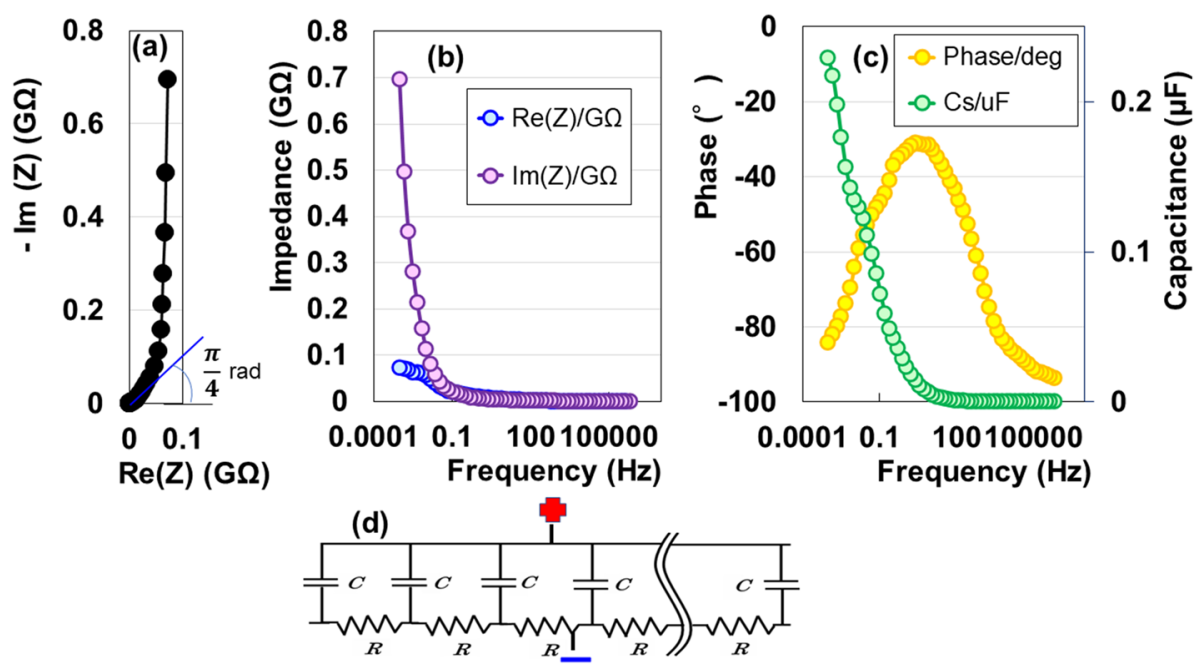

Figure 4. (a) Nyquist plot, (b) Bode plot, and (c) phase and series capacitance as a function of frequency for AAO device. (d) Electric distributed constant equipment circuit organized on the AAO surface.

and energy-rich storage effects for the AAO of interest are promising for future electronic devices and electric power applications such as hybrid electric vehicles and backup power supplies ${ }^{1}$.

Complex evaluation of electric storage. To analyse non-destructively the electrostatic contribution of the specimen, we finally performed the AC impedance measurement from $1 \mathrm{mHz}$ to $1 \mathrm{MHz}$ using Nyquist and Bode diagrams at $293 \mathrm{~K}$. We present a complex-plane (Nyquist) plot of the impedance data in Fig. 4a. The frequency dependent impedance is characterized by the combined pattern of a line with a slope of $\pi / 4 \mathrm{rad}$ and a straight vertical line. The $\pi / 4$ rad region (Warburg region) indicates the distributed resistance/capacitance in the porous electrode ${ }^{26,27}$. This suggests that the electrode is an AAO film with a porous surface with a high resistance. A nearly vertical line for the impedance data is produced by a series RC circuit, as well as a graphene EDLC ${ }^{28}$. The rapid increases in imaginary impedance compared with the real impedance, in the lower frequency region of the Bode diagram (Fig. 4b), suggests an evidence for DC charging. Moreover, the decrease in the phase angle to $-90^{\circ}$ with decreasing frequency indicates another evidence of DC charging (Fig. 4c). Thus, the AAO device offers a nearly ideal electric distributed-constant structure for electric storage (Fig. $4 \mathrm{~d}$ ). The series capacitance was $0.23 \mu \mathrm{F}$ at $1 \mathrm{mHz}$ (Fig. 4c).

\section{Methods}

The fabrication of AAO specimens and analyses of the charging/discharging behaviour were reported in previous papers ${ }^{4-6}$. Electron-irradiation was performed using JEOL (JEM-2100) transmission electron microscopy (TEM) at 100-200 keV. Electron diffraction patterns, on a fluorescent screen, created from an irradiated area under an electron density of $10^{9} \mathrm{e} / \mathrm{m}^{2} \mathrm{~s}$ were evaluated by radial distribution function analysis ${ }^{29}$. The optimised local atomic configurations of the $\mathrm{AlO}_{6}$ clusters were determined through a plane-wave-based first-principles density functional calculation (VASP 5.3$)^{30}$ in a $\gamma$-alumina-based system with $\mathrm{O}$ vacancies.

Received: 9 July 2020; Accepted: 6 January 2021

Published online: 18 January 2021

\section{References}

1. Conway, B. E. Electrochemical Supercapacitors: Scientific Fundamentals and Technological Applications (Plenum Press, New York, 1999).

2. Aricó, A. S., Bruce, P., Scrosati, B., Tarascon, J.-M. \& Van Schalkwijk, W. Nanostructured materials for advanced energy conversion and storage devices. Nat. Mater. 4, 366-377. https://doi.org/10.1038/nmat1368 (2005).

3. El-Kady, M. F., Strong, V., Dubin, S. \& Kaner, R. B. Laser scribing of high-performance and flexible graphene-based electrochemical capacitors. Science 335, 1326-1330. https://doi.org/10.1126/science.1216744 (2012).

4. Fukuhara, M. et al. Amorphous aluminium-oxide supercapacitors. Europhys. Lett 123, 58004. https://doi.org/10.1029/02955075/123/58004 (2018).

5. Fukuhara, M. et al. Anodic oxidization of Al-Y amorphous alloy ribbons and their capacitive properties. J. Alloy. Comp 776, 757-762. https://doi.org/10.1016/j.jallcom.2018.10.346 (2019).

6. Fukuhara, M. et al. Effects of temperatures and carbon dioxide nanobubbles on superior electric storage for anodically oxidized films of $\mathrm{AlY}_{10}$ amorphous alloy. AIP Adv. 9, 095202. https://doi.org/10.1063/1.5102082 (2019).

7. Fukuhara, M., Kuroda, T. \& Hasegawa, F. Amorphous titanium-oxide supercapacitors. Sci. Rep. 6, 35870. https://doi.org/10.1038/ srep35870 (2016).

8. Nakamura, R., Ishimaru, M., Yasuda, H. \& Nakajima, H. Atomic rearrangements in amorphous $\mathrm{Al}_{2} \mathrm{O}_{3}$ under electron-beam irradiation. J. Appl. Phys. 113, 064312. https://doi.org/10.1063/1.4790705 (2013). 
9. Vashishta, P., Kalia, R. K., Nakano, A. \& Rino, J. P. Interaction potentials for alumina and molecular dynamics simulations of amorphous and liquid alumina. J. Appl. Phys. 103, 083504. https://doi.org/10.1063/1.2901171 (2008).

10. Tane, M. et al. Nanovoid formation by change in amorphous structure through the annealing of amorphous $\mathrm{Al}_{2} \mathrm{O}_{3}$ thin films. Acta Mater. 59, 4631-4640. https://doi.org/10.1016/j.actamat.2011.04.008 (2011).

11. Nakamura, R. et al. Enhancement of nanovoid formation in annealed amorphous $\mathrm{Al}_{2} \mathrm{O}_{3}$ including W. J. Appl. Phys. 110, 064324. https://doi.org/10.1063/1.3639290 (2011).

12. Lamparter, P. \& Kniep, R. Structure of amorphous $\mathrm{Al}_{2} \mathrm{O}_{3}$. Phys. B 234-236, 405-406 (2006).

13. Yang, Z. Q., He, L. L., Jin, Z. X. \& Ye, H. Q. Effect of electron beam irradiation on the interphase boundary between crystalline $\mathrm{Al}$ and amorphous $\mathrm{Al}_{2} \mathrm{O}_{3}$. J. Phys. Condens. Matter. 13, 8475-8479. https://doi.org/10.1088/0953-8984/13/37/304 (2001).

14. Mochel, M. E., Humphreys, C. J., Eades, J. A., Mochel, J. M. \& Petford, A. M. Electron beam writing on a $20-\AA ̊$ scale in metal B-aluminas. Appl. Phys. Lett. 42, 392-394. https://doi.org/10.1063/1.93918 (1983).

15. Howitt, D. G., Chen, S. J., Gierhart, B. C., Smith, R. L. \& Collins, S. D. The electron beam hole drilling of silicon nitride thin films. J. Appl. Phys. 103, 024310. https://doi.org/10.1063/1.2828157 (2008).

16. Fukuhara, M. et al. Amorphous titanium-oxide supercapacitors with high capacitance. EuroPhys. Lett. 128, 58001. https://doi. org/10.1209/0295-5075/128/58001 (2019).

17. Wasserman, H. J. \& Vermaak, J. S. On the determination of a lattice contraction in very small silver particles. Surf. Sci. 22, 164-172 (1970).

18. Wasserman, H. J. \& Vermaak, J. S. On the determination of the surface stress of copper and platinum. Surf. Sci. 32, 168-174 (1972).

19. Vermaak, J. S. \& Wisdorf, D. K. Measurement of the average surface stress of gold as a function of temperature in the temperature range 50-985'. J. Phys. Chem. 72, 4150-4154 (1968).

20. Fukuhara, M. Lattice expansion of nanoscale compound particles. Phys. Lett. A 313, 427-430 (2003).

21. Wei, X. \& Yuan, Z. H. Electronic transport behaviour of diameter-graded Ag nanowires. Phys. Lett. A. 374, 2267-2276 (2010).

22. Braun, E., Eichen, Y., Sivan, U. \& Ben-Yoseph, G. DNA-templated assembly and electrode attachment of a conducting silver wire. Nature 391, 775-778. https://doi.org/10.1038/35826 (1998).

23. Dupeyrat, M. \& Nakache, E. Electrocapillarity and electroadsorption. J. Colloid. Interface Sci. 73, 332-344 (1980).

24. Fukuhara, M., Kuroda, T., Hasegawa, F. \& Sueyoshi, T. Superior electric storage on an amorphous perfluorinated polymer surface. Sci. Rep. 6, 22012. https://doi.org/10.1038/srep22012 (2016).

25. Whittingham, M. Materials challenges facing electrical energy storage. MRS Bull. 33, 411-419. https://doi.org/10.1557/mrs2008.82 (2008).

26. Kötz, R. \& Carlen, M. Principles and applications of electrochemical capacitors. Electrochim. Acta. 45, 2483-2498. https://doi. org/10.1016/S0013-4686(00)00354-6 (2000).

27. Itagaki, M. Electrochemistry, Impedance Method 2nd edn. (Maruzen, Tokyo, 2012).

28. Miller, J. R., Outlaw, R. A. \& Holloway, B. C. Graphene double-layer capacitor with ac line-filtering performance. Science 329, 1637-1639. https://doi.org/10.1126/science.1194372 (2010).

29. Shanmugam, J., Borisenko, K. B., Yu-Jen, C. \& Kirkland, A. I. eRDF Analyser: An interactive GUI for electron reduced density function analysis. Softw. X 6, 185-192 (2017).

30. Gutiérrez, G. \& Johansson, B. Molecular dynamics study of structural properties of amorphous $\mathrm{Al}_{2} \mathrm{O}_{3}$. Phys. Rev. B 65, 104202. https://doi.org/10.1103/PhysRevB.65.104202 (2002).

\section{Acknowledgements}

The authors would like to thank students, Kohei Suzuki and Naoya Koiso from Shizuoka University for their help with the first-principles simulations of $\mathrm{AlO}_{6}$ clusters. We would like to thank Editage (www.editage.com) for English language editing.

\section{Author contributions}

M.F. performed the electric storage analysis and wrote the paper. F.H. edited the paper, and T.K. performed the electric measurements. T.H. assisted with anodic oxidation. M.T. conducted the TEM and electron irradiation analyses. K.K. prepared amorphous ribbons. N.F. performed the MD simulations. All authors discussed the results and commented on the manuscript. M.F. supervised all the work.

\section{Competing interests}

The authors declare no competing interests.

\section{Additional information}

Supplementary Information The online version contains supplementary material available at https://doi. org/10.1038/s41598-021-81483-2.

Correspondence and requests for materials should be addressed to M.F.

Reprints and permissions information is available at www.nature.com/reprints.

Publisher's note Springer Nature remains neutral with regard to jurisdictional claims in published maps and institutional affiliations.

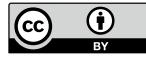

Open Access This article is licensed under a Creative Commons Attribution 4.0 International License, which permits use, sharing, adaptation, distribution and reproduction in any medium or format, as long as you give appropriate credit to the original author(s) and the source, provide a link to the Creative Commons licence, and indicate if changes were made. The images or other third party material in this article are included in the article's Creative Commons licence, unless indicated otherwise in a credit line to the material. If material is not included in the article's Creative Commons licence and your intended use is not permitted by statutory regulation or exceeds the permitted use, you will need to obtain permission directly from the copyright holder. To view a copy of this licence, visit http://creativecommons.org/licenses/by/4.0/.

(C) The Author(s) 2021 